\title{
A Casa de Geraldo de Paula Souza: texto e imagem sobre um sanitarista paulista
}

\author{
The House of Geraldo de Paula Souza: text and image of \\ a sanitarian from São Paulo
}

Lina Faria

Historiadora, pesquisadora Fapesp de Pós-Doutorado Departamento de Política Científica e Tecnológica, Unicamp

Rua Pandiá Calógeras, 51

Cidade Universitária Zeferino Vaz

13083-970 - Campinas - SP -

Brasil

lfaria@ige.unicamp.br
FARIA, L. : A Casa de Geraldo de Paula Souza: texto e imagem sobre um sanitarista paulista.

História, Ciências, Saúde - Manguinhos,

v. 12, n. 3, p. 1011-24, set.-dez. 2005.

O presente texto busca estudar um capítulo importante da institucionalização da 'ciência aplicada' no Brasil. Não se trata de um estudo dos pressupostos ou paradigmas científicos, mas de imagens da história da institucionalização da ciência em São Paulo. O texto trata de uma instituição fortalecida ao longo de várias décadas, sob uma liderança que Robert K. Merton chamaria de 'catalisadora'. Através do riquíssimo material iconográfico deixado pelo médico sanitarista Geraldo Horácio de Paula Souza foi possível reconstruir um período importante da atuação profissional desse grande sanitarista à frente do Instituto de Higiene - embrião da atual Faculdade de Saúde Pública da USP - e os primeiros tempos de criação dessa instituição paulista.

PALAVRAS-CHAVE: Instituto de Higiene de São Paulo; Geraldo Horácio de Paula Souza; história da saúde pública; memória da saúde.

FARIA, L.: The House of Geraldo de Paula Souza: text and image of a sanitarian from São Paulo.

História, Ciências, Saúde - Manguinhos,

v. 12, n. 3, p. 1011-24, Sept.-Dec. 2005.

The article looks at an important chapter in the institutionalization of 'applied science' in Brazil. It is not a study of scientific suppositions or paradigms but of images from the history of the institutionalization of science in São Paulo. It examines an institution that was strengthened over a number of decades, under a leadership that Robert K. Merton was to call 'catalyzing'. Using invaluable iconographic material left by the sanitarian and physician Geraldo Horácio de Paula Souza, it was possible to reconstruct not only an important period in the professional life of this great sanitarian, who was at the helm of the Institute of Hygiene (embryo of the Universidade de São Paulo's present Public Health School), but also the early days of the creation of this São Paulo institute.

KEYWORDS: São Paulo Hygiene Institute; Geraldo Horácio de Paula Souza; history of health; memory of health. 


\section{Introdução}

$\mathrm{U}$

m período importante da atuação profissional de um institutionbuilder brasileiro - o médico sanitarista Geraldo Horácio de Paula Souza - é o foco do presente trabalho, de texto e imagem baseados no material iconográfico da família, bem como em documentos do Rockefeller Archive Center, nos Estados Unidos. Em trabalhos anteriores, já discutimos a atuação profissional de Paula Souza no Instituto de Higiene de São Paulo e no Serviço Sanitário Estadual, instituições em que se destacou o papel do médico sanitarista, ao construir o campo de administração em saúde em São Paulo e apresentar, em especial, sua proposta de um novo modelo de atendimento à população - os centros de saúde. Além disso, mostramos, em tais trabalhos, o papel dinâmico de Paula Souza na criação de um ambiente adequado à produção científica no Instituto de Higiene de São Paulo e os laços estreitos que construiu, ao longo de sua trajetória pessoal e institucional, com a Fundação Rockefeller. ${ }^{1}$

Até se poderia atribuir ao presente trabalho um caráter laudatório, se por esse termo se entender nosso esforço em resgatar a atuação do sanitarista na institucionalização da saúde pública em São Paulo, na primeira metade do século XX. Parece-nos, no entanto, que se trata de um esforço necessário de preencher uma lacuna, que apenas recentemente, junto a outros autores, vimos tentando eliminar. O trabalho focaliza os momentos decisivos de consolidação do Instituto de Higiene de São Paulo e do surgimento da 'Higiene' como disciplina acadêmica. O Instituto de Higiene participou de forma atuante nesse processo de reconfiguração do campo médico, de instauração de novas práticas e concepções e de formação de novos profissionais - os profissionais de saúde pública. Durante a gestão de Paula Souza (1922-1951) a instituição sofreu uma transformação qualitativa tanto em termos físicos - com a construção de um novo prédio - quanto em termos acadêmicos, com a consolidação de um modelo de atuação em saúde pública que ele organizou e conduziu. Geraldo Horácio de Paula Souza foi para o Instituto de Higiene de São Paulo o que Arnaldo Vieira de Carvalho foi para a Faculdade de Medicina e Cirurgia de São Paulo e Oswaldo Cruz para o Instituto de Manguinhos. Ainda hoje, membros mais antigos da Faculdade de Medicina e da Casa de Oswaldo Cruz cultuam e preservam a memória desses cientistas: são os rituais de consagração discutidos pela antropologia clássica. Aquelas instituições ficaram conhecidas, respectivamente, como 'Casa de Arnaldo' e 'Casa de Oswaldo Cruz'. A historiografia, até recentemente, silenciava sobre a trajetória de Geraldo Horácio de Paula Souza e seu papel transformador, ao planejar os necessários 'compartimentos' de sua Casa de ciência - laboratórios, centro de 
saúde, biblioteca especia-lizada e salas de demonstração para educação sanitária, entre outros. O presente ensaio é uma contribuição à historiografia e um convite a que, doravante, denominemos aquela instituição de ciência e de saúde pública, a 'Casa de Geraldo'.

\section{Os passos da institucionalização}

A 'Casa de Geraldo' bem poderia ter sido o outro nome da Faculdade de Saúde Pública da Universidade de São Paulo, em referência a Geraldo Horácio de Paula Souza, um dos seus mais ativos empreendedores. A atual Faculdade de Saúde Pública, por sua vez, originou-se do Instituto de Higiene, criado em 1918, por convênio firmado entre o governo do Estado de São Paulo, a Faculdade de Medicina e Cirurgia ${ }^{2}$ e o International Health Board - IHB da Fundação Rockefeller. O Instituto de Higiene de São Paulo é um caso bem-sucedido da união de recursos internacionais - a 'filantropia científica' norte-americana - e dos objetivos modernizadores da elite paulista. ${ }^{3}$

O Instituto de Higiene de São Paulo foi a segunda instituição a receber auxílio da Rockefeller, tendo sido precedido apenas pela Universidade Johns Hopkins, e o primeiro órgão da Faculdade de Medicina e Cirurgia de São Paulo a dispor de regime de tempo integral para pesquisa e docência. A Universidade Johns Hopkins, criada em 1916, com recursos da Fundação Rockefeller, operou como referência institucional e pedagógica para a atuação da Fundação no Brasil e em outras partes do mundo, no campo da saúde pública.

Concebido inicialmente como uma cadeira de Higiene na própria Faculdade de Medicina, em poucos anos o Instituto de Higiene tornava-se uma instituição autônoma e firmava-se no cenário nacional das instituições de saúde. Em São Paulo, particularmente, desempenhou papel fundamental na formulação da política sanitária estadual, adotada a partir de 1925, quando a educação sanitária veio a ser a pedra de toque da política pública em saúde.

Por solicitação de Arnaldo Vieira de Carvalho, ${ }^{4}$ diretor da Faculdade de Medicina e Cirurgia, o IHB, da Fundação Rockefeller, estabeleceu os primeiros contatos de cooperação. O objetivo era implantar, além da Cadeira de Higiene e Anatomia, outra de Histologia Patológica. Ambas seriam ministradas por professores norte-americanos. ${ }^{5} \mathrm{O}$ acordo previa que a Faculdade, através do governo estadual, ficaria responsável pela doação de um prédio adequado para a instalação da Cadeira de Higiene. Ao IHB caberia o fornecimento de equipamentos, o pagamento dos salários dos docentes e a concessão de bolsas de estudos em higiene e saúde pública para profissionais brasileiros. ${ }^{6}$

Geraldo Horácio de Paula Souza e Francisco Borges Vieira foram os nomes indicados pelo diretor da Faculdade de Medicina e 
Cirurgia de São Paulo para serem bolsistas da Fundação Rockefeller no primeiro curso em Higiene e Saúde Pública realizado pela recém-inaugurada School of Hygiene and Public Health, da Universidade Johns Hopkins. Paula Souza e seu companheiro de lutas pela saúde, Borges Vieira, tiveram atuação destacada não só no Instituto de Higiene de São Paulo, mas no Serviço Sanitário do Estado de São Paulo, na Sociedade Brasileira de Higiene e no emergente campo da cooperação internacional em saúde.

De volta ao Brasil, em 1922, Geraldo Horácio de Paula Souza assumiu a direção da instituição, permanecendo no cargo até 1951, ano de sua morte. Retornou ao país com novas metodologias na área da higiene e da saúde pública, baseadas na profilaxia de doenças infecciosas, no emprego de técnicas laboratoriais em microbiologia, na educação sanitária e na formação de profissionais na área da saúde pública. Essas metodologias de pesquisa e de intervenção sanitária eram executadas nos centros de saúde e postos de higiene. Foi no Serviço Sanitário paulista (1922-1927) e no Instituto de Higiene de São Paulo (1922-1951) que as atividades de Paula Souza tiveram maior impacto. Dois anos depois de seu retorno, conseguiu que o Instituto de Higiene fosse oficializado ${ }^{7}$ e implantou o regime de trabalho em tempo integral na instituição. Nessa mesma época, organizou o Curso de Educadoras Sanitárias que se consubstanciou numa das expressões da nova política de saúde pública. ${ }^{8}$

No período em que esteve à frente da instituição, pleiteou a favor da construção de um novo prédio, independente da Faculdade de Medicina, com todo o aparelhamento necessário para a melhor difusão do ensino e da pesquisa, contando até mesmo com um Centro de Saúde Modelo - o primeiro centro de saúde criado no Brasil - para treinamento de alunos. ${ }^{9}$

Em 1925, não mais associado à Faculdade de Medicina, o Instituto de Higiene de São Paulo iniciou um programa de pesquisas independente, ampliando suas atribuições, garantindo seu espaço no campo das pesquisas sanitárias e na formação de pessoal na área da saúde pública. Nos anos seguintes, continuou a receber apoio técnico e financeiro da Fundação Rockefeller, novas bolsas de estudo foram concedidas e novos cursos foram organizados.

Num primeiro momento, o Instituto foi instalado no prédio da Rua Brigadeiro Tobias, $n^{\circ} 45$, em frente à Faculdade de Medicina, num casarão pertencente ao Barão de Piracicaba. Mas em maio de 1925 Paula Souza apresentou aos membros da Rockefeller uma proposta de construção de um prédio independente para o Instituto.

O Conselho Diretor do IHB aprovou a ajuda para construção do edifício. O plano de cooperação previa, entre outros pontos, que a construção do novo Instituto seria em Araçá, como uma estrutura independente da Faculdade de Medicina; que o custo da 
construção e os equipamentos seriam financiados pela Rockefeller, com o apoio do governo estadual, e, finalmente, que o Instituto manteria atividades de ensino e pesquisa direcionados para estudantes e graduados em medicina. ${ }^{10}$

Diante do auxílio financeiro proporcionado pela Fundação Rockefeller, o governo do estado cedeu um extenso terreno situado na Avenida Dr. Arnaldo, porque ali seriam localizados os diversos blocos do centro médico de São Paulo: Faculdade de Medicina, Instituto 'Adolfo Lutz', Hospital 'Emílio Ribas' (Isolamento), Instituto Médico-Legal 'Oscar Freire', Instituto de Higiene e Hospital das Clínicas. ${ }^{11}$

Três anos após a aprovação da proposta de Paula Souza foi assinado o contrato entre o governo estadual e o IHB para construção do novo prédio. ${ }^{12}$ As obras tiveram início em 1928 e foram totalmente finalizadas em 1932. A construção obedeceu ao seguinte critério:

Um edifício de três andares - podendo suportar um quarto quando, pelo seu desenvolvimento, isso se tornar necessário. No terceiro andar encontram-se os laboratórios de pesquisas, seções de fisiologia aplicada à higiene, de química sanitária, higiene do trabalho, nutrição e dietética, microbiologia e imunologia aplicadas à higiene, de leprologia e micologia, de técnica sanitária e finalmente, uma pequena unidade hospitalar, onde podem ser recolhidos até seis doentes que se tenha em mira submeter a estudos. No segundo: laboratórios de ensino, salas de aulas teóricas, de desenho, de fotografia, seções de estatística, de epidemiologia, da Carta sanitária e de inquéritos e investigações sociais, salas de cursos práticos para estatística, química e fisiologia aplicadas à higiene, e outras adequadas a trabalhos de microscopia. No primeiro: salão para conferencias públicas, biblioteca, salas de aulas teóricas e praticas do curso de educadores sanitários, seção de higiene rural e parasitologia, fabrico de meios de cultura, aparelhos de esterilização e lavagem de material, além de parte do centro de saúde, que ocupa, também, o porão. Destarte, ingressando-se no prédio, vai-se gradativamente encontrando-se, assim, para pesquisas (terceiro andar) ambiente adequado, de maior sossego. ${ }^{13}$

A mudança para o prédio, ainda em obras, em 1931, foi realizada em meio às disputas pela posse do edifício. Alguns setores da administração pública consideravam que a edificação, projetada para ser uma Escola de Higiene, poderia abrigar um hospital ou seções do Serviço Sanitário. ${ }^{14}$

Paula Souza foi responsável pela concepção das plantas do novo prédio do Instituto de Higiene. Como vimos, o primeiro andar foi destinado, exclusivamente, para atividades de atendimento ao público (Centro de Saúde Modelo, Curso para Educadores Sanitários 
e Sala de Conferências). O segundo foi reservado para o ensino (Cadeira de Higiene da Faculdade de Medicina, além dos cursos de Epidemiologia, Estatística e Parasitologia) e o terceiro, para a pesquisa (seções de Epidemiologia, Bacteriologia, Psicotécnica e Parasitologia).

Entre as principais atividades do Instituto estavam a instrução, a pesquisa ${ }^{15} \mathrm{e}$ atividades em saúde pública. Os cursos de higiene e saúde pública contavam com aulas de administração sanitária, bacteriologia e imunologia, epidemiologia e profilaxia de várias doenças infecciosas, entre elas a pneumonia, a influenza, a tuberculose, a difteria, a varíola, a febre tifóide, a cólera, a febre amarela, a dengue, a filariose, a peste, o tifo, a doença de Chagas, a tripanossomíase e a raiva. ${ }^{16}$

As atividades em saúde pública incluíam as 'inspeções sanitárias'. Essas inspeções, realizadas em localidades do estado de São Paulo e mesmo de outros estados, pelos alunos do curso de higiene da Faculdade de Medicina, tinham como objetivo familiarizar o estudante em métodos de investigação. $\mathrm{O}$ trabalho de inspeção representava um exercício, cujo objetivo era o desenvolvimento das habilidades de observação, indagação, comparação, registro e sistematização. A inspeção possibilitava um mapeamento da situação sanitária local e, ao mesmo tempo, fornecia ao Instituto de Higiene dados sobre abastecimento de água, sistemas de tratamento dos esgotos, métodos de tratamento do lixo, estatísticas vitais, condições sanitárias das fábricas e habitações coletivas, higiene das escolas, mercados, matadouros e portos (Campos, 2002).

No que se refere às estatísticas vitais, além da sistematização de dados estatísticos sobre a mortalidade infantil em São Paulo e sobre as taxas de mortalidade por doenças como febre tifóide, tuberculose, malária, lepra e varíola, o estudante ficava responsável, ainda, pela distribuição de impressos com propagandas sobre higiene. ${ }^{17}$ O objetivo era o de criar uma consciência sanitária para que o indivíduo pudesse, através dos métodos de higiene apreendidos, evitar que as doenças se propagassem.

Desde os primeiros anos de funcionamento o ensino foi o propósito fundamental do Instituto de Higiene. Os cursos se articulavam em torno de três áreas principais: a higiene municipal, a higiene rural e a epidemiologia. A preocupação com os problemas rurais foi objeto de pesquisas e cursos intensivos voltados para a profilaxia e prevenção da malária, da febre amarela e do tracoma, além de orientações para construção de latrinas, fossas e métodos de drenagem do solo.

No Instituto funcionava o 'Centro Acadêmico Oswaldo Cruz'. Além de afeito às questões de interesse dos estudantes, era responsável pela manutenção de vários postos de profilaxia da sífilis no Estado de São Paulo, pela publicação de boletins médicos, pela 


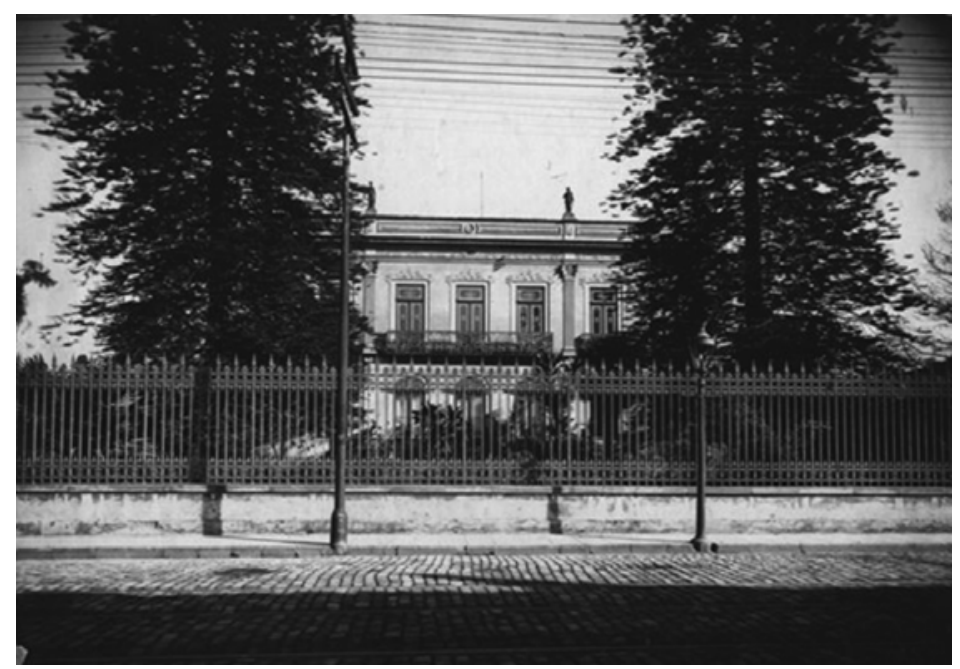

Fachada da primeira sede do Instituto de Higiene. Rua

Brigadeiro Tobias, n. 45, em frente à Faculdade de Medicina, num casarão pertencente ao Barão de Piracicaba.

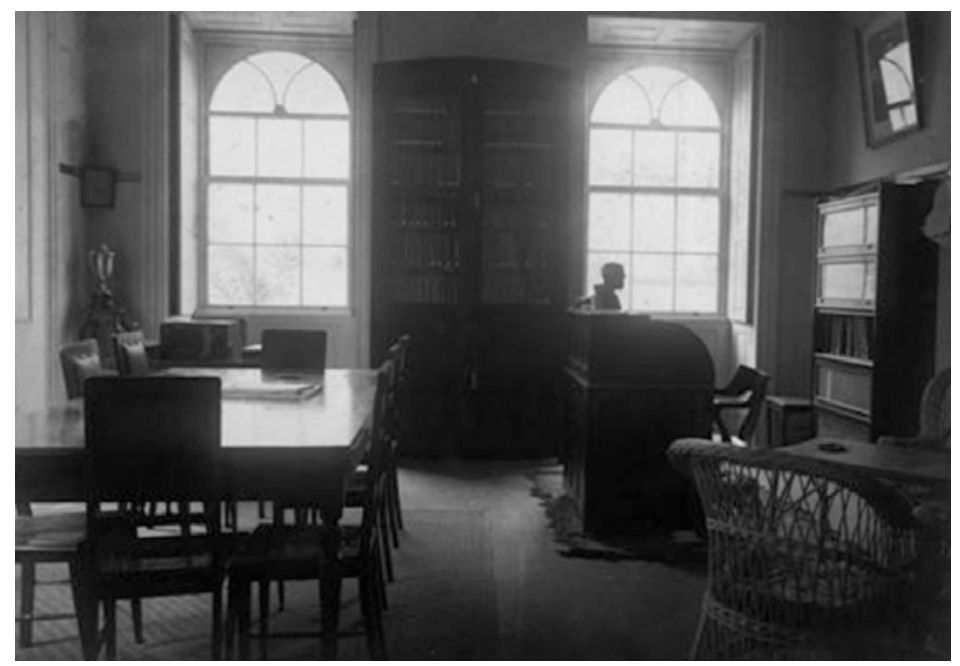

Diretoria do

Centro

Acadêmico

Oswaldo Cruz.

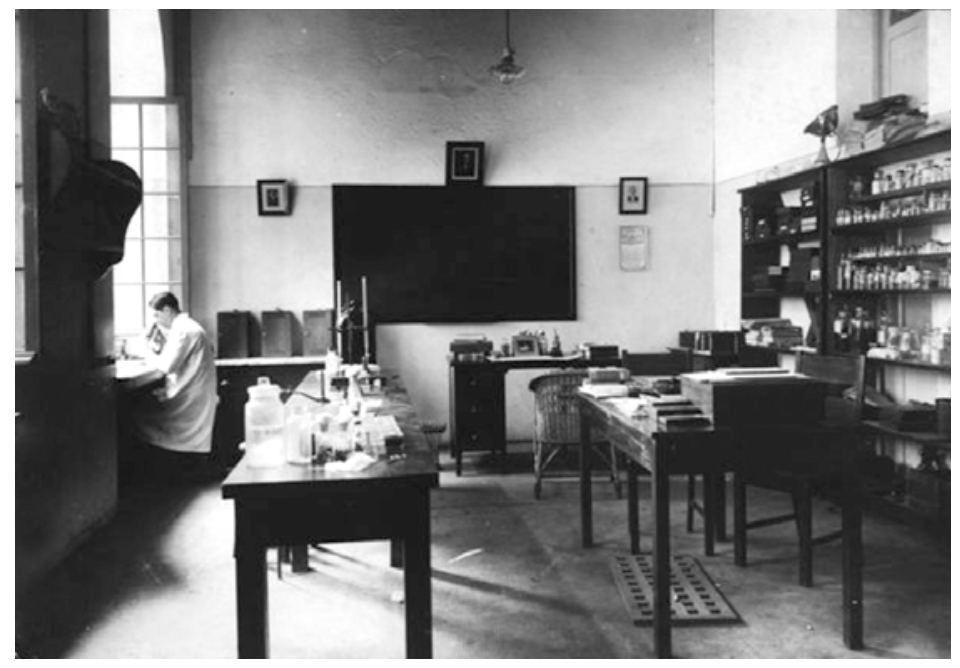

Laboratório de Parasitologia. 
LINAFARIA

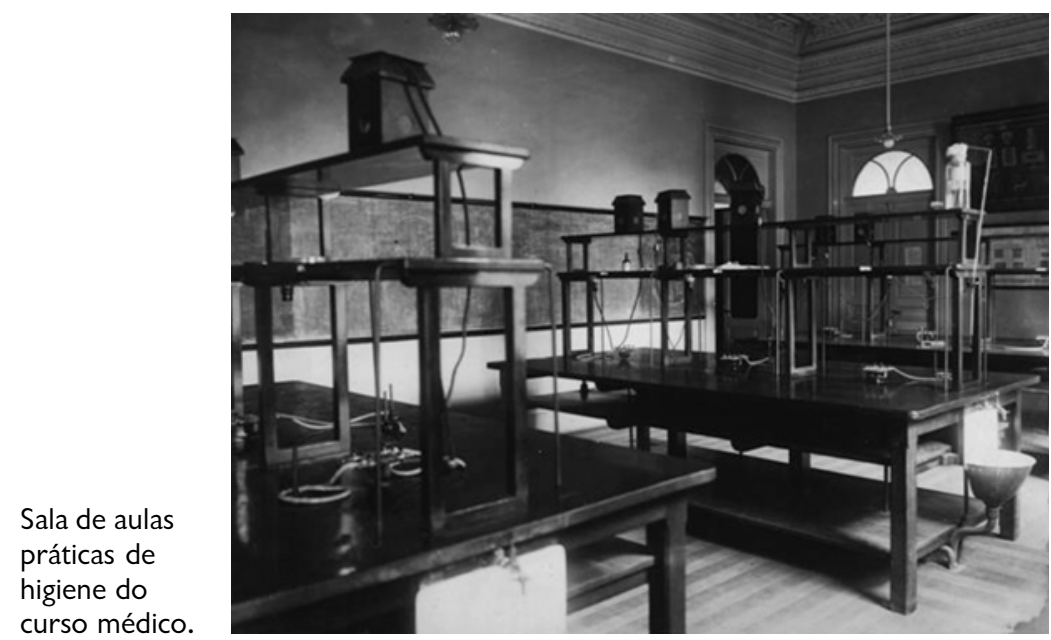

Construção do Instituto

de Higiene. Ao fundo, casa

que pertenceu a Tarsila do

Amaral e Oswald de Andrade.

Atual Centro de Saúde

Escola Geraldo Horácio de

Paula Souza.

Antigo

laboratório de bacteriologia e sorologia, atual laboratório de higiene social.

Biblioteca do Instituto de Higiene.
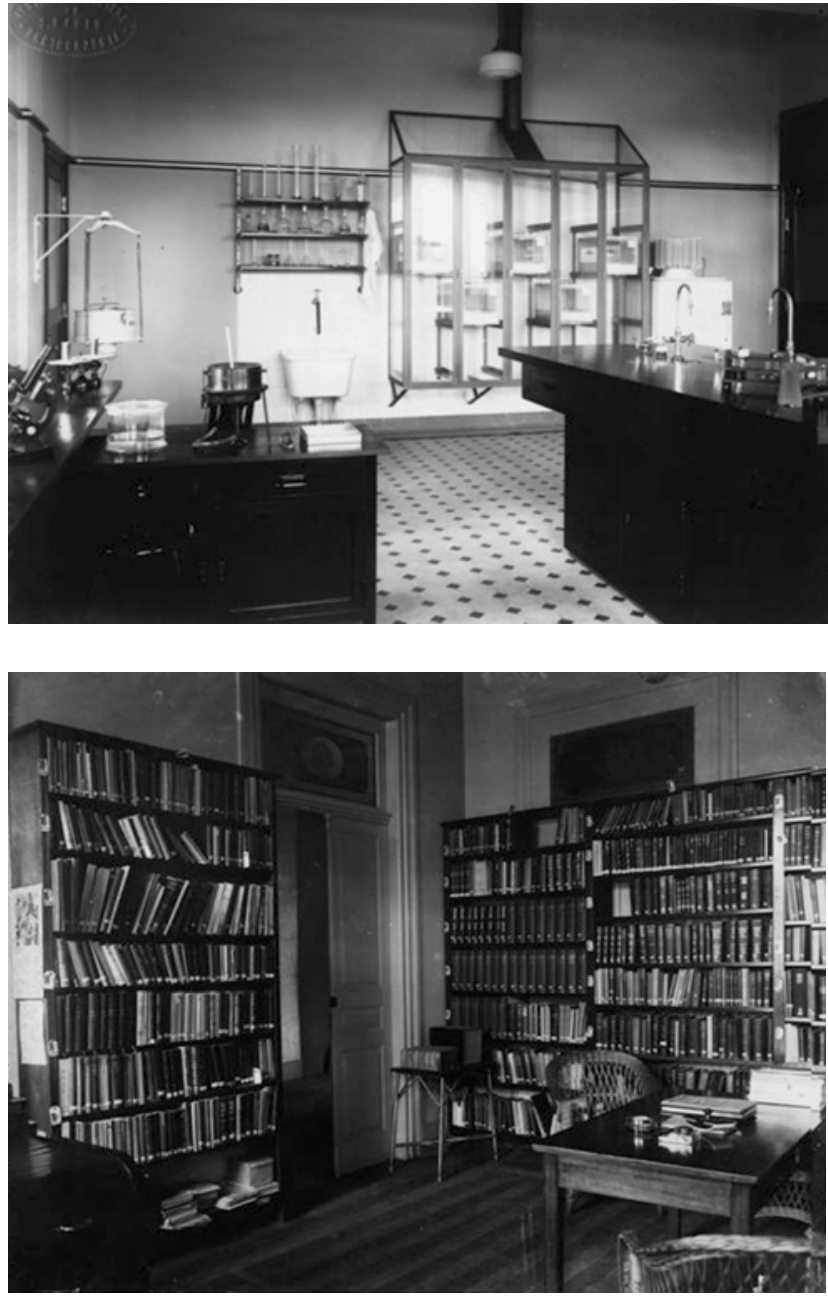
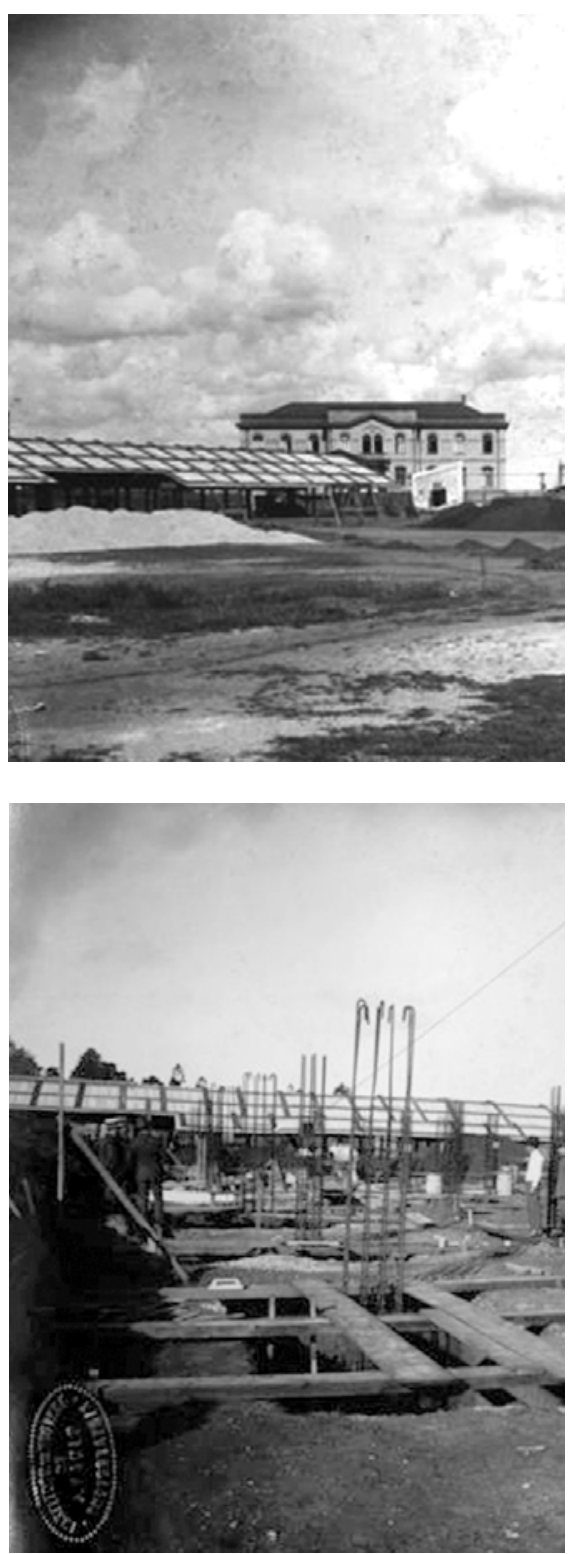

Construção do Instituto de Higiene. 
Construção do

Instituto de Higiene.
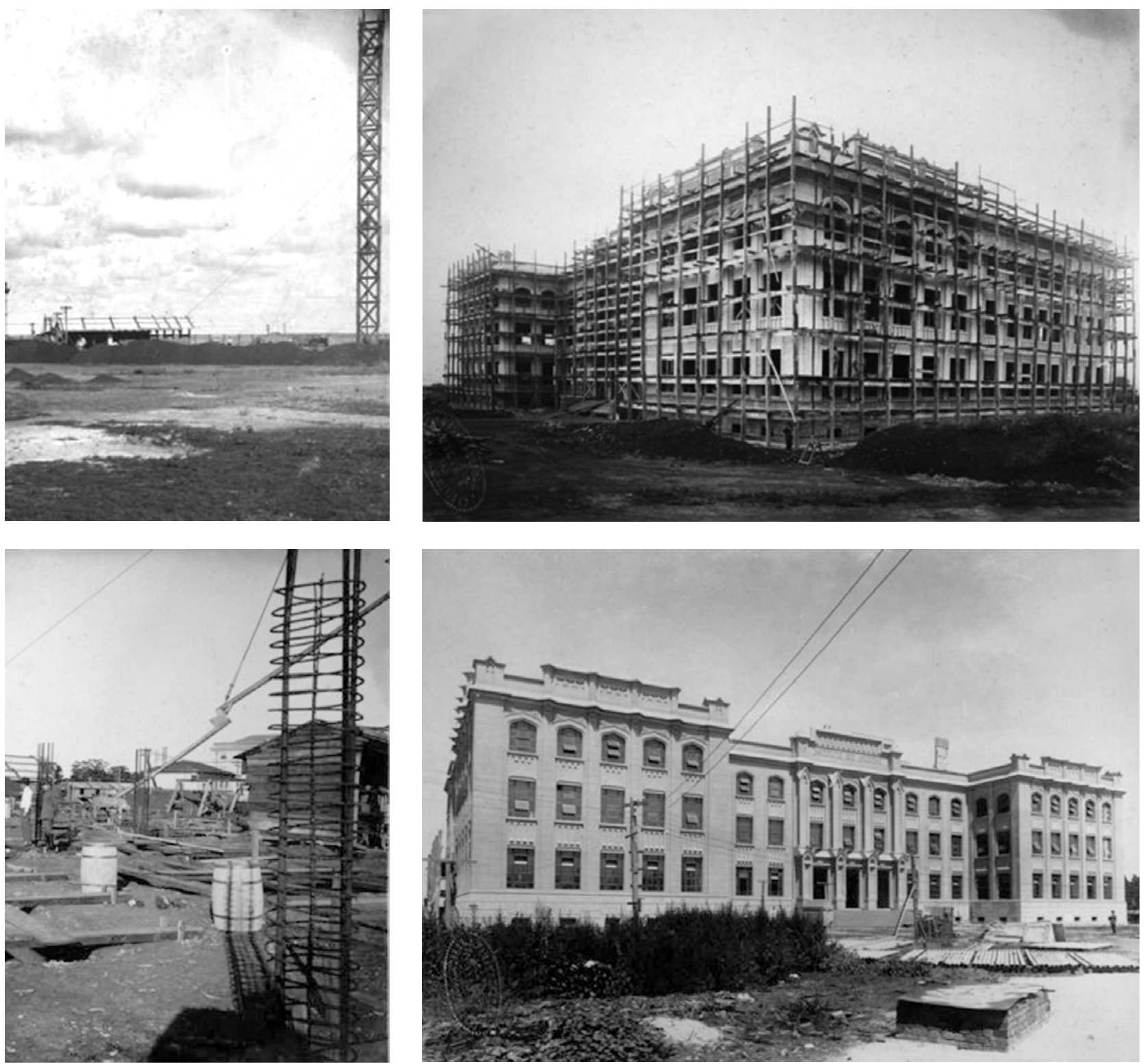

Construção do

Instituto de Higiene. 


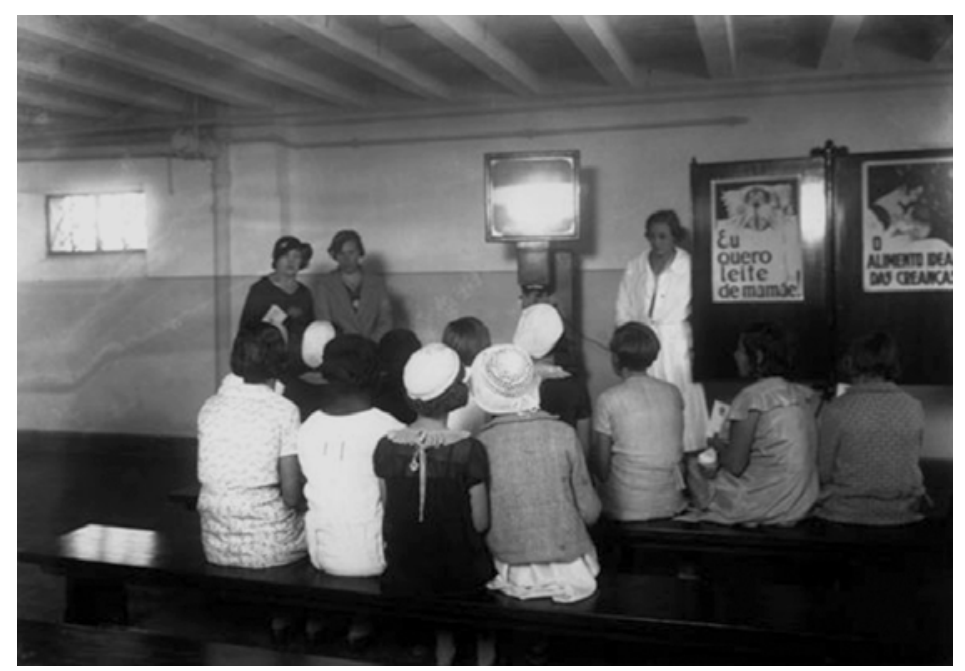

Oficinas de

debates sobre

higiene.

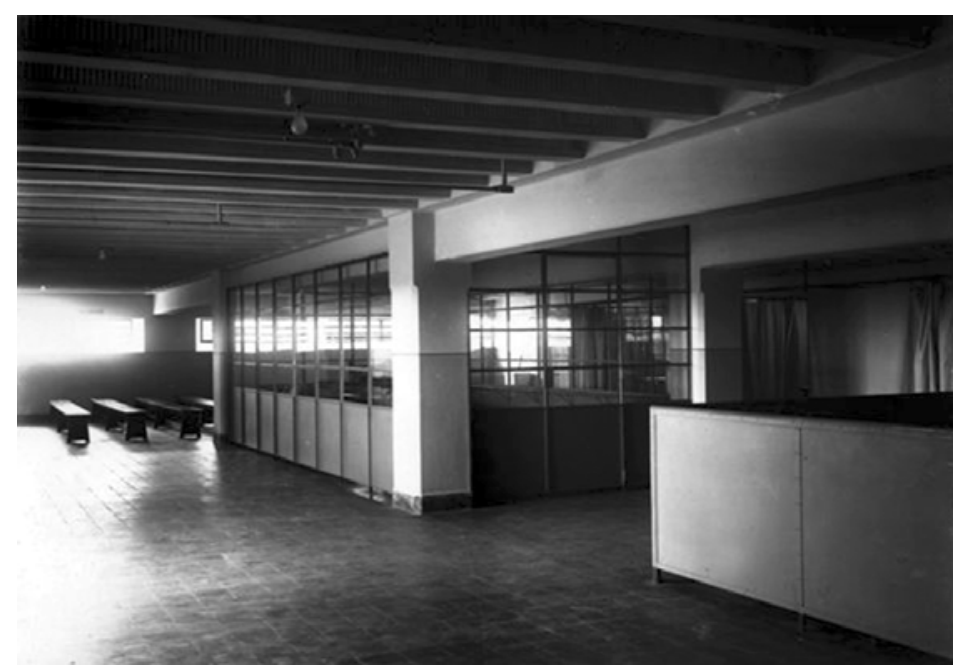

Sala de

Educação

Sanitária.

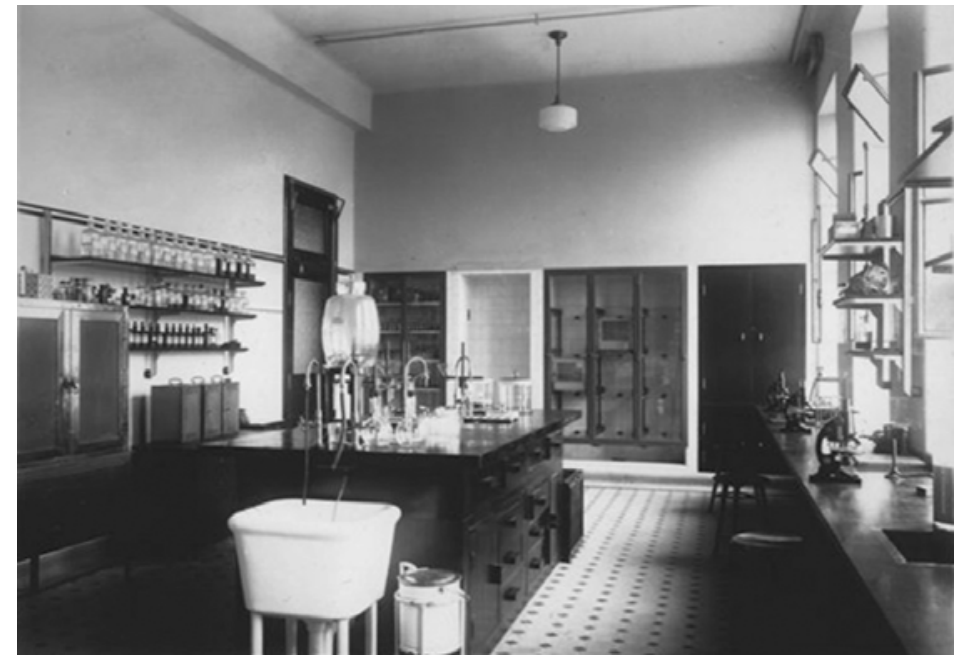

Higiene Rural e

Parasitologia. 
distribuição de medicamentos e prestação de serviços à população pobre da capital, e pela manutenção de postos médicos e campanhas sanitárias. ${ }^{18}$

No início dos anos 40, o Instituto de Higiene havia diplomado 49 sanitaristas, 466 educadoras sanitárias e 45 nutricionistas, bem como, fornecido certificado a 49 outros médicos que seguiram os cursos de emergência ou intensivos ali ministrados. ${ }^{19}$ Por sua orientação original, pela posição inovadora nos anos iniciais e pela qualidade do ensino e das pesquisas desenvolvidas mais tarde, o Instituto de Higiene, atual Faculdade de Saúde Pública da USP, tornou-se uma instituição fundamental no desenvolvimento da área biomédica no Brasil.

\section{Conclusão}

O maior legado da parceria de São Paulo com a Fundação Rockefeller foi, sem dúvida, a criação do Instituto de Higiene de São Paulo. A elevação da instituição à categoria de Faculdade de Higiene e Saúde Pública, em $1945,{ }^{20}$ foi o marco da institucionalização da disciplina de Higiene em São Paulo. Por meio da atuação dos profissionais brasileiros, tendo à frente Geraldo Horácio de Paula Souza, a influência da Fundação Rockefeller revelou-se na adoção de carreiras de pesquisa em regime de tempo integral para a pesquisa e a docência, bem como na importância dada à formação de educadoras sanitárias, enfermeiras em saúde pública e à educação de profissionais para os serviços sanitários no estado de São Paulo.

A institucionalização da saúde pública como disciplina acadêmica na 'Casa de Geraldo' ajudou a manter vivos os debates em torno das questões de saúde, definindo um campo de influência no estado e, mais tarde, em todo o país. Com efeito, no final dos anos 40 o Instituto de Higiene já se projetava como um centro de excelência no cenário nacional, desempenhando um papel importante no desenvolvimento das políticas de saúde pública e da pesquisa laboratorial e na sedimentação de carreiras científicas.

Esse modelo adquiriu grande legitimidade porque o grupo de profissionais liderados por Geraldo Horácio de Paula Souza era animado por um forte etos, com interesses e aspirações comuns pela chamada 'ciência sanitária' e por sua aplicação; possuíam, em suma, expectativas e percepções semelhantes quanto aos objetivos das políticas de saúde e à atuação profissional, que privilegiava a dedicação exclusiva, a pesquisa experimental e o trabalho de campo. O grupo de Paula Souza soube costurar o necessário respaldo político durante várias administrações estaduais e, mesmo durante o período getulista, os laços com o governo federal, embora tensos, não chegaram a constituir um obstáculo à gestão do sanitarista paulista, à frente da Faculdade de Saúde Pública. 
* Este trabalho é fruto de pesquisas realizadas nos arquivos do Centro de Memória da Saúde Pública da Faculdade de Saúde Pública da USP e do Museu de Saúde Pública de São Paulo. Faz parte de um conjunto de estudos, que Luiz Antonio de Castro Santos e eu dirigimos na Uerj e na Unicamp, sobre a formação histórica da saúde pública no Brasil.
O presente texto trata de uma instituição fortalecida ao longo de várias décadas, sob uma liderança atuante e determinada. Não que a trajetória institucional tivesse sido um caminho fácil, sem altos e baixos, sem crises 'externas' (particularmente com o Serviço Sanitário do Estado) ou com outros grupos de pesquisadores emergentes (como o Instituto Bacteriológico). ${ }^{21}$ Em que pesem as crises institucionais, houve um ambiente favorável ao crescimento profissional de seus cientistas. Pesquisa e ensino eram igualmente estimulados. Os trabalhos de seus pesquisadores ampliaram significativamente o saber na área biomédica, abrindo caminhos para a saúde pública. Para usar uma expressão corrente nos dias atuais, o Instituto de Higiene tornou-se uma 'referência nacional'.

Lembremos aqui, como apontamos anteriormente, que Geraldo Horácio de Paula Souza foi para a Faculdade de Saúde Pública o que Arnaldo Vieira de Carvalho foi para a Faculdade de Medicina e Cirurgia de São Paulo e Oswaldo Cruz para o Instituto de Manguinhos. Quando morreu, em 1951, Paula Souza era um cientista de renome, conhecido em centros científicos nos Estados Unidos e na Europa, especialmente graças às pesquisas desenvolvidas no Instituto de Higiene e por sua atuação internacional. Foi na figura de Paula Souza que o etos profissional dos sanitaristas brasileiros firmou-se definitivamente.

Em 2005 comemoram-se os oitenta e sete anos de criação do Instituto de Higiene de São Paulo e os sessenta anos de criação da Faculdade de Saúde Pública da Universidade de São Paulo. O presente trabalho é uma homenagem a essa grande instituição, no momento em que os rituais de criação e institucionalização deverão ser justamente relembrados por toda a comunidade científica e pelos militantes da reforma sanitária no Brasil.

\section{NOTAS}

${ }^{1}$ Ver Faria, 1999, 2001 e 2002.

2 A Faculdade de Medicina e Cirurgia de São Paulo foi criada em 1912, através da lei $n^{0} 1.357$ assinada pelo Presidente Francisco de Paula Rodrigues Alves e pelo secretário do Interior Altino Arantes. Seu primeiro diretor foi Arnaldo Vieira de Carvalho. Em 1934, a Faculdade foi integrada na Universidade de São Paulo pelo decreto $n^{\circ}$ 6.283, de 25 de janeiro. Ver " 25 anos de atividades - A Faculdade de Medicina da Universidade de São Paulo festeja hoje o 25 aniversário de sua instalação". Inventário Capanema, GC 38. 04. 02. Doc. 140, CPDOC. Ver também Candeias, 1984 e Marinho, 1993. Ver, ainda, "A Casa de Arnaldo no Centenário do Conhecimento". Revista do Conselho Regional de Medicina do Estado de São Paulo (CREMESP), abr./maio/jun., ano VII, n. 27, 2004

${ }^{3}$ Sobre a elite governante em São Paulo e o projeto modernizador em saúde, ver Castro Santos (2004) e Love (1982).

${ }^{4}$ Em carta enviada à Fundação Rockefeller, datada de 24 de novembro de 1916, Arnaldo Vieira de Carvalho solicitou uma conferência com membros do IHB para tratar da possibilidade de organização de uma cadeira de Higiene na Faculdade de Medicina. Rockefeller Archive Center (RAC), Series 305, R.G. 1.1, Box 17, Folder 151A. Ver também: RAC, Series 305, R.G. 1.1, Box 17, Folder 151, 28.1.1919. 
${ }^{5}$ RAC, Annual Report, 1916. Series 305, R.G. 1.1, Box 12.

${ }^{6} \mathrm{O}$ acordo previa que a Faculdade de Medicina contribuiria com cerca de 37 mil dólares e o International Health Board, com 150 mil. "Institute of Hygiene, São Paulo, Project Report". RAC, Series 305, R.G. 1.1, Box 17, Folder 151-A, 1916-1928. Ver ainda "Institute of Hygiene: São Paulo". RAC, Series 305, R.G. 1.1, Box 17, Folder 151-A, 22.5.1917.

7 Pela Lei 2.108. Coleção de Leis e Decretos do Estado de São Paulo. Atos do Poder Legislativo, Imprensa Nacional, 1924

8 Ver Faria, 2005. Ver também Castro Santos \& Faria, 2005.

${ }^{9}$ Ver Castro Santos \& Faria, 2003. Nesse texto discutimos o movimento que deu origem aos centros de saúde no Brasil, a posição de prestígio que desfrutaram os sanitaristas e a enfermagem de saúde pública e o papel desempenhado pela Fundação Rockefeller nesse processo. Traçamos, ainda, um quadro comparativo entre a experiência paulista e o health center movement, nos estados norte-americanos de Wisconsin e Ohio, chamando a atenção para os programas e as medidas sanitárias implementadas nessas regiões.

10 O Conselho Diretor do IHB aprovou a quantia de 5.300 contos de réis para a construção dos institutos de Anatomia, Fisiologia, Química, Patologia e Higiene. Desse total, 1.500 foram direcionados para a construção do novo prédio do Instituto de Higiene, que ao contrário dos outros institutos seria uma unidade autônoma da Faculdade de Medicina de São Paulo. "São Paulo negotiations - Higiene/ R.A. Lambert to R. M. Pearce July 14, 1925". RAC, Series 305, R.G. 1.1, Box 18, Folder 153, 7.8.1925. Ver também carta de Pedro Dias ao diretor do IHB George E. Vincent. RAC, Series 305, R.G. 1.1, Box 18, Folder 152/153, 11.9.1925. Ver Candeias, 1984.

11 “1925-1975 - Cinqüentenário da Faculdade de Saúde Pública”. Revista de Saúde Pública, v. 9, n. 2, 1975.

$12 \mathrm{O}$ contrato previa a quantia de 2.300 contos de réis para as obras. Desse total, 1.500 foram financiados pela Fundação Rockefeller e o restante, pelo governo estadual. Carta de Fred L. Soper a Russell. RAC, Series 305, R.G. 1.1, Box 20, Folder 159, 15.10.1928.

13 Revista de Higiene e Saúde Pública, 1928, p. 151-2. Órgão da Sociedade Brasileira de Higiene. Ver também, Carta de Paula Souza a Russell. RAC, Series 305, R.G. 1.1, Box 18, Folder 152/153, 5.1.1925 e, ainda, Candeias, 1984.

14 Sobre isso ver Candeias, 1984; Faria, 2003.

15 Os departamentos de Parasitologia, dirigido por Samuel Pessoa, e de Epidemiologia e Bacteriologia, chefiado por Francisco Borges Vieira, desenvolveram vários estudos sobre a utilidade do óleo de quenopódio no tratamento da ancilostomíase, além de pesquisas sobre a profilaxia da malária, da febre tifóide e de doenças peculiares às condições rurais no Brasil. Além disso, os departamentos davam assistência às atividades na área de higiene rural empreendidas pelo governo federal, em vários estados brasileiros.

16 Carta de Wilson Smillie a Wickliffe Rose. RAC, Series 305, R.G. 1.1, Box, 18, Folder 152-153, 23.2.1921. Ver também "Resumé of the Annual Report of the Department of Hygiene for the year ending". RAC, Series 305, R.G. 1.1, Box 19, Folder 154, 31.12.1919.

17 Paula Souza, G. H., "Relatório apresentado ao Secretário do Interior, José Manuel Lobo, sobre as atividades do Instituto de Higiene entre os anos de 1921 e 1925". RAC, Series 305, R.G. 1.1, Box 24, Folder 142, 1925. Ver ainda Paula Souza \& Borges Vieira, 1944; 1948.

18 Mensagem apresentada ao Congresso Legislativo, em 14.7.1925, por Carlos de Campos, governador do estado de São Paulo, transcrita no Correio Paulistano, 1925.

19 "A criação de uma Escola de Higiene destinada a formar profissionais especializados", Folha da Manhã, São Paulo, 7.3.1943.

20 Pelo decreto 14.857 de 10.7.1945. Coleção de Leis e Decretos do Estado de São Paulo. Atos do Poder Legislativo, Imprensa Nacional, 1945.

${ }^{21}$ Essas crises institucionais foram tratadas em outro trabalho (Faria, 1999). Nele procuramos indicar que, malgrado os conflitos internos e externos que atravessaram a vida institucional, a instituição firmou-se nacional e internacionalmente. Acreditamos que as imagens do Instituto de Higiene, neste artigo, retratam, justamente, os 'alicerces' sólidos que suportaram, sem fraturas maiores, os embates e conflitos institucionais da 'Casa de Geraldo'.

22 Imagens cedidas pelo Centro de Memória da Saúde Pública da Faculdade de Saúde Pública da USP e pelo Museu de Saúde Pública Emílio Ribas. 


\section{REFERÊNCIAS BIBLIOGRÁFICAS}

Campos, Cristina de 2002

Candeias, Nelly M. Ferreira

1984

Castro Santos, Luiz A. de; Faria, Lina

Castro Santos, Luiz A. de Faria, Lina $2003 b$

Castro Santos, Luiz A. de Faria, Lina 2004

Faria, Lina 1999

Faria, Lina 2001

Faria, Lina 2002

Faria, Lina 2003

Faria, Lina 2005

Love, Joseph

1982

Mascarenhas, Rodolfo dos Santos

Mascarenhas, Rodolfo dos Santos 1959

Paula Souza, Geraldo Horácio de; Borges Vieira, Francisco 1944

Paula Souza, Geraldo Horácio de; Borges Vieira, Francisco 1948

Vasconcellos, Maria da 1995
São Paulo pela lente da higiene: as propostas de Geraldo de Paula Souza para a cidade (1925-1945). São Carlos: RiMa.

Memória histórica da Faculdade de Saúde Pública da Universidade de São Paulo (1918/1954). Revista de Saúde Pública, v. 18, n. especial), p. 2-60. São Paulo.

Os primeiros centros de saúde nos Estados Unidos e no Brasil: um estudo comparativo. Teoria e Pesquisa, n. 40/41. São Carlos: Ed. Ufscar, p. 137-81.

A Cooperação Internacional e a Enfermagem de Saúde Pública no Rio de Janeiro e São Paulo. Horizontes (CDAPH: Universidade São Francisco), Bragança Paulista. v. 22, n. 2, julho/dezembro, p. 123-48.

Poder, ideologias e saúde no Brasil da Primeira República: ensaio de história sociológica. In: Hochman, Gilberto; Diego Armus (org.) Cuidar controlar, curar: ensaios históricos sobre saúde e doença na América Latina e Caribe. Rio de Janeiro: Ed. Fiocruz, p. 249-93.

O Instituto de Higiene: contribuição à história da ciência e da administração em saúde em São Paulo. Physis (Revista de Saúde Coletiva), v. IX, n. 1, p. 175-208. Rio de Janeiro: IMS.

Scientific Traditions in Brazil: The History of the Instituto de Higiene in São Paulo. Rockefeller Archive Center Research Reports Online, n. 1, April, p. 1-6. Tarrytown, NY: Rockefeller Archive Center, Rockefeller University

A Fundação Rockefeller e os serviços de saúde em São Paulo (1920-30): perspectivas históricas. História, Ciências, Saúde - Manguinhos, v. IX, n. 3, set.-dez., p. 561-90. Rio de Janeiro.

Ciência, ensino e administração em saúde: a Fundação Rockefeller e a criação do Instituto de Higiene de São Paulo. Tese de Doutorado, Instituto de Medicina Social, Uerj, Rio de Janeiro.

Educadoras Sanitárias e Enfermeiras de Saúde Pública: identidades profissionais em construção. Apresentado no $10^{\circ}$ Seminário Nacional de História da Ciência e da Tecnologia. Faculdade de Filosofia e Ciências Humanas, UFMG, 17-19 out.

A locomotiva: São Paulo na federação brasileira 1889-1937.

(Trad. Vera Alice Cardoso da Silva.) Rio de Janeiro: Paz e Terra.

Contribuição para o estudo da administração sanitária estadual em São Paulo. Tese de Livre Docência, Faculdade de Higiene e Saúde Pública, USP, São Paulo.

Contribuição ao estudo da história do ensino de educação sanitária na Faculdade de Higiene e Saúde Pública da Universidade de São Paulo. Arquivos da Faculdade de Higiene e Saúde Pública, v. 13, n. 1, p. 243-62. São Paulo: USP.

Centros de saúde. 'Eixo' da organização sanitária. Boletim do Instituto de Higiene, n. 59. São Paulo: Imprensa Oficial do Estado de São Paulo.

Formação de técnicos para os serviços de saúde pública. Revista de Higiene e Saúde Pública, ano VI, n. 1, p. 30-8.

Memórias da saúde pública: a fotografia como testemunha. São Paulo: Hucitec, Rio de Janeiro: Abrasco. 